\title{
The influence of hormonal mechanisms in arterial hypertension in patient with mental disorders
}

\author{
Roxana Mihaela Barbu, Cristina Maria Gavrilescu, \\ Paloma Horjinec, Raducu I. Popescu, Wlather Bild
}

\begin{abstract}
Roxana Mihaela Barbu - MD, PhD, Department of Physiology, University of Medicine and Pharmacy „Grigore T. Popa”, Iași, Specialist in Clinical Pharmacology, Romania.

Cristina Maria Gavrilescu - Lecturer, MD, PhD, „Grigore T. Popa” University of Medicine and Pharmacy, Iași, Vth Medical and Geriatrics - Gerontology Clinic, Iași, Romania.

Paloma Horjinec - M.D., Ph. D., Lecturer, "Grigore T. Popa" University of Medicine and Pharmacy, Iași; 1st Medical Department, Vth Medical and Geriatrics - Gerontology Clinic, Iași, Senior in Internal Medicine, Specialist in Cardiology, "Promedicanon" Private Office, Iași, Romania.

Raducu I. Popescu - MD, PhD, University of Medicine and Pharmacy „Grigore T. Popa”, Iași, Romania.

Walther Bild - MD, PhD, Professor Department of Physiology, University of Medicine and Pharmacy „Grigore T. Popa”, Iași, Romania.
\end{abstract}

\begin{abstract}
At the same time as the incidence of cardiovascular diseases increases, associated secondary psychiatric disorders are more and more frequent. This article highlights the interplay between hormonal mechanisms and psychiatric disorders in patients with essential hypertension. Hypertension has been recognized as a multi-factorial trait resulting from the effect of a combination of environmental and genetic factors, including excess dietary salt or alcohol intake, stress, age, genetics and family history, obesity, physical inactivity, as well as high saturated fat diet. During the past few years, however, a large amount of information has been collected on the vascular inflammation, indicating that inflammation may involve in the initiation as well as development of hypertension and allowing us to reconsidering the pathogenic mechanisms of hypertension. High blood pressure is a major cardiovascular risk factor with an increasing incidence in the aging population. Blood pressure is the pressure
\end{abstract}


\% exerted by blood on the artery walls during contraction and rhythmic relaxation of the heart. Hypertension occurs when the strength of the blood is stronger than it should be normally. Its causes cannot be easily identified and the prevalence of the disease tends to increase with age. The etiology of high blood pressure in more than $90 \%$ of cases cannot be attributed to a unique, identifiable cause. The mechanisms involved are numerous: genetic predisposition, vascular remodeling, endothelial dysfunction, renal retention of water and salt, dysfunction of the renin angiotensin-aldosterone system, sympathetic autonomic hypertonia and insulin resistance. These incriminated mechanisms are frequently associated with hypertensinogenic factors such as obesity, sedentary lifestyle, increased salt intake, dyslipidemia, increased alcohol consumption. The key element in the hormonal mechanisms is the renin-angiotensin aldosterone system being the main system responsible for the hydrosaline retention and blood pressure increase. However, angiotensin II can also be produced at the tissue level independent of the conversion enzyme. This can significantly contribute to the onset and progression of high blood pressure and ventricular hypertrophy. Conclusions. In this regard, the studies illustrate the activation of the renin-angiotensin system in prehypertensive subjects and the benefits of drug limitation of angiotensin II actions in an early phase, in order to delay the progression to high blood pressure.

\section{KEYWORDS}

Hypertension, mechanisms, renin system - angiotensin.

\section{INTRODUCTION}

In the specialized literature we encounter the following personality disorders of the anankast type, addictive, impulsive, hysterical, which have a direct connection with the cardiovascular diseases. These personality deviations in essential hypertension occur quite frequently, have a polymorphic, unstable character and influence the onset of the disease, the particularities of the clinical picture, the evolution and prognosis of the disease. Clinical investigations of essential hypertension highlight the following neurotic conditions, such as: anxiety, asthenic, obsessive and affective disorders - depression (16). Due to the symptomatic polymorphism, these syndromes serve as a nucleus that associates other neurotic, affective, somato-vegetative states, which, in turn, lead to the formation of different variants in the composition of each of them.
Anxious syndrome is one of the most specific in the context of essential hypertension. It manifests itself in the form of different type variants: anxious-depressive, anxioushypochondriac, anxious-obsessive, anxiousphobic, anxious-hysterical.

The asthenic syndrome has been divided into three stages: compensated, subcompensated, decompensated. Two clinical variants were also highlighted: hyperstenic and hypostatic.

The obsessive syndrome in patients with high blood pressure essential in its evolution has a number of features. In some cases, it manifests as a syndrome predominantly with obsessive ideas, in other cases in association with affective and neurotic symptoms. In these patients more frequent are the variants such as: obsessive, obsessive-phobic, obsessive-anxious (16).

Traditionally, arterial hypertension and subsequent end-organ damage have been 
Bulletin of Integrative Psychiatry O New Series O March 2020 ○ Year XXVI ONo. 1 (84)/53

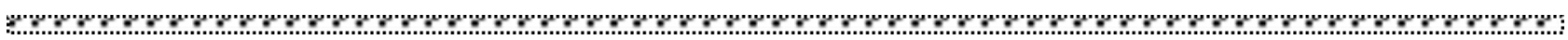

attributed to hemodynamic factors, but increasing evidence indicates that inflammation also contributes to the deleterious consequences of this disease. The immune system has evolved to prevent invasion of foreign organisms and to promote tissue healing after injury. However, this beneficial activity comes at a cost of collateral damage when the immune system overreacts to internal injury, such as prehypertension. Renal inflammation results in injury and impaired urinary sodium excretion, and vascular inflammation leads to endothelial dysfunction, increased vascular resistance, and arterial remodeling and stiffening. Reninangiotensine-aldosteron system (RAAS) has a major role in physiological functions control and in pathological situations, through vascular tone maintenance, vascular wall and myocardium remodelling, atherosclerosis, glomerulosclerosis and other diseases. Precious informations about tissue analog systems, which could syntetize renin, angiotensine and aldosteron, occured around 1980. A major role in theses system activity is played by himaza enzyme, which syntetize AT II, without angiotensine converting enzyme. RAAS tissue systems have an important role in cardiovascular pathology, nephropathy, diabetes mellitus, obesity (1).

RAAS was initially identified as essential for circulation homeostasis. Renin is an enzyme and not a vasoactive substance. It is a kidney released enzyme when blood pressure is very low. The major amount of renin is in blood and after that it leaves the kidney, being spread to whole body. In juxtaglomerular renal cells, renin is synthetized and deposited, in inactive form, called prorenin. These cells are modified smooth muscle cells, located in afferent arteriolar walls. When blood pressure drops, intrinsic renal reactions determine the activation of proreni towards rennin. Sympathetic nervous system stimulation is followed by rennin releasing and angiotensine II formation; so, sodium will suffer an increased tubular reabsorbtion. Renin stimulates angiotensin I formation, followed by angiotensin II. The latest provokes efferent arteriolar constriction, with hydrostatic glomerular pressure increasing and glomerular filtration is normal (2).

The conversion of angiotensin I to angiotensin II is inside the lungs, the reaction being catalyzed by conversion enzyme, produced by pulmonary endothelium. Angiotensin I produces moderate vasoconstriction, without significant modifications of circulatory function (3). During its bloodstream persistence angiotensin II is a powerful vasoconstrictor, both arterial and venous (a weaker effect comparative with arteries). Through all these effects, circulatory blood volume is increased and blood pressure also, for the next hours and days. When inside the blood is an excess of angiotensin, the whole renovascular mechanism is adapted for a higher level of blood pressure $(4,5)$.

Angiotensin II stimulates sodium transport through luminal membranes and also through laterobazal membranes of tubular cells (6). The direct effect of angiotensin towards the kidney and also via aldosteron is important for long term regulation of blood pressure (7). When AARS is blocked, the same increasing of saline intake determines 10 fold increasing of the pressure, until 50-60mmHg $(8,9)$.

Angiotensin converting enzyme inhibitors (ACEI) in 1977 occurred the first ACEI, captoril, ACEI diminish angiotensin II and kinaze production, by diminishing bradikinin. Nowadays, ACEI are utilized not only for blood pressure control, but also for the protection of patients with subclinic target organs and for secondary prophylaxis after 
r

myocardial infarction, stroke and in heart

failure (10).

\section{ANGIOTENSIN II ANTAGONIST RECEPTOR (AAR).}

They represents an important class of antihypertensive drugs, well tolerated. AT1 receptor activation determines vasoconstriction, catecholamine releasing, antidiuretic hormone production, vascular remodeling and myocardial hypertrophy. AAR antagonize all these effects, their administration is followed by smooth vascular muscle relaxation, increasing of salt excretion, diminishing of remodeling and hypertrophy (11). Selective blockade of AT1, determines a compensatory increasing of angiotensin II, with AT2 stimulation. They also determine vasodilation via bradikinin and nitric oxide. They have similar efficacy as ACEI, on patients with myocardial infarction and heart failure with very high cardiovascular risk, the outcome is more favorable than after ACEI (12).

\section{INHIBITORS OF ALDOSTERONE RECEPTORS.}

Aldosterone diminishes potassium and magnesium levels, increases salt reabsorption and catecholamine synthesis. After intravenous administration of angiotensin II, aldosteron and sodium levels are increased. Vascular remodeling, myocardial hypertrophy and suprarenalian hyperplasia occurs. Arterial hypertension, produced by aldosteron has a difficult answer to medication (13).

AARS is implicated in heart failure, arterial hypertension and renal disease, through angiotensin II and aldosteron. Their activity is prominent towards target organs, provoking endothelial dysfunction, vasoconstriction, muscle hypertrophy and fibrosis. Taking into account the interferences of the pathogenetic mechanisms of the arterial hypertension essential with those of the neurotransformation and affective states, encountered in the patients with hypertension, and the pharmacokinetic and pharmacodynamic mechanisms of the used drugs, there are in the specialized literature appropriate treatment schemes associated with the clinical syndromes.

Angiotensin II is a powerful vasoconstrictor, produces blood pressure rising, atherosclerosis. According to European guidelines for arterial hypertension management 2018, angiotensin converting enzyme inhibitors treatment reduces cardiovascular events and death (14).

Active medication against AARS actions by blocking its major pathways. ACEI, AAR and aldosteron antagonists are very efficient in controlling blood pressure. They improve outcome in many conditions associated with AARS excessive stimulation: left ventricular hypertrophy, diabetic nephropathy, heart failure and myocardial infarction (15).

Among the affective states in essential hypertension, depression is associated with the association of different clinical variants. More commonly, depressive, depressiveanxious, astheno-depressive, depressivehypochondriac, depressive-phobic syndrome are encountered. Depressive-apathetic, depressive-dysphoric and depressivehysteriform states are less common (16).

\section{ACKNOWLEDGEMENTS AND DISCLOSURES}

The authors declare that they have no potential conflicts of interest to disclose. 
Bulletin of Integrative Psychiatry O New Series O March 2020 O Year XXVI ONo. 1 (84)/55

\section{REFERENCES}

1. Abdalla S, Lother H, Abdel-tawab AM et al. The angiotensin II AT2 receptor is an AT1 receptor antagonist. J Biol Chem, 2001; 43: 39721-6.

2. Barbu RM, Gavrilescu CM, Paraschiv C, Popescu IR, Bild W. Influence of angiotensin upon uterine smooth muscle. The Medical-Surgical Journal 2019;123(2):43-53.

3. Ababei DC, Lefter R, Ciobica A, Antioh I, Barbu RM, Arcan OD, Beșchea Chiriac S, Zbârcea C, Bild W, Bild V. Effects of Renin-Angiotensin system blockade on anxiety and memory in mice. Farmacia 2017:65;381-389.

4. Cristina Maria Gavrilescu, Maura G Felea, Roxana Barbu, Odetta Duma, Maria Mădălina Bodescu, M Midilina Bodescul, R Ghiuru, C Boerescu, C Paraschiv. Assessment of adverse drug reactions as cardiovascular risk factors. Rev Med Chir Soc Med Nat Iasi 2016/1/1; 120:48-54.

5. Hughes AD. How do thiazide and thiazide-like diuretics lower blood pressure. J Renin Angiotensin Aldosterone Syst. 2004;5:155-160.

6. Pecker MS. Pathophysiologic effects and strategies for long-term diuretic treatment of hypertension. In: Laragh JH, Brenner BM, eds. Hypertension: Pathophysiology, Diagnosis, and Management. New York, NY: Raven Press; 1990:2143-2168.

7. World Health Organization Collaborating Centre for International Drug Monitoring, the Uppsala Monitoring Centre (WHO-UMC). The use of the WHO-UMC system for standardised case causality assessment 2010.

8. Gard PR, Daw P, Mashhour ZS, Tran P. Interactions of angiotensin IV and oxytocin on behaviour in mice. J Renin Angiotensin Ald Syst, 2007; 8:133-138.

9. Jackson EK and Garrison JC. Renin and angiotensin. In: Goodman and Gillman's The Pharmacological Basis of Therapeutics, 1996; 31: 733-58.

10. Wray S, Kupittayanant S, Shmygol A, Smith RD, Burdyga T (2001). The physiological basis of uterine contractility: a short review. Exp Physiol 86:239-46.

11. Vancea, Florin, Elemente de psihopatologie şi psihiatrie, Ed. Psihomedia, Sibiu, 2008.

12. Vancea, Florin, Bazele psihopatologiei, Ed. Psihomedia, Sibiu, 2011.

13. Tudose, F, Psihopatologie şi psihiatrie pentru psihologi, Ed. Infomedica, Buc., 2002.

14. Widdop RE, Matrougui K, Levy BI, Henrion D. AT2 receptor-mediated relaxation is preserved after long-term AT1 receptor blockade. Hypertension. 2002; 40: 516-520.

15. Pagliaro P, Penna C. Rethinking the renin-angiotensin system and its role in cardiovascular regulation. Cardiovasc Drugs Ther. 2005;19:77-87.

16. Dimsdale JE. Psychological Stress and Cardiovascular Disease. J Am Coll Cardiol. 2008; 51 (13): $1237-1246$.

\section{Correspondence:}

Cristina Maria Gavrilescu,

MD, PhD, University of Medicine and Pharmacy „Grigore T. Popa”, Iasi, Universitatii street no 16, 700115, Iași, Romania, cristina.gavrilescu@umfiasi.ro

Submission: 18 jan 2020

Acceptance: 03 mar 2020 